series, and the expansions of the elementary functions in power series. Infinite products are treated in the same elementary way. Next comes a more extensive study of infinite series, containing a brief survey of the present situation as far as the convergence and divergence of series is concerned. A chapter on series of functions leads naturally to a brief discussion of Fourier series. Similarly, the treatment of series of complex numbers leads to the mention of Dirichlet and factorial series. The book closes with a chapter on divergent series. Problems are provided at the close of each chapter, to lead the reader into a deeper consideration of the subject.

There is much of value in this book for the person who wants an introduction to the study of infinite series, and the person who wants a survey and derivation of much scattered material of interest in this field. Altogether it is a book very much to be recommended to the person who is making his acquaintance with higher mathematics along analysis lines.

T. H. HILDEBRandT

Early Science in Oxford. Part II. Mathematics. By R. T. Gunther. London, Oxford University Press, 1922. 101 pp., 10 plates, colored frontispiece.

The early history of American mathematics is most intimately linked with the development of mathematical science in England. Not only the terminology, inevitably, but equally the content of our early text-books was based directly upon the English models which themselves served as texts in the period from 1650 to 1750 or even later. For this reason details concerning early Oxford, so long the center of mathematics in England, are of particular interest to us.

The illustrations of this work are fine and well chosen; the lists of the early mathematicians and astronomers of Oxford are a welcome addition to the literature of the subject. Unfortunately the text (pp. 1-33) reveals an amazing lack of familiarity with recent publications on the history of mathematics, abounding in errors which could have been avoided by reference to books on the shelves of the Bodleian. However, the descriptive catalogue of early mathematical instruments belonging to the University and Colleges of Oxford, the real raison d'être of the work in question, is made with great ability and care. This material constitutes a most worthy addition to our knowledge of mathematical instruments' which played so large a part in the discovery and exploration period of American history.

It is not worth while to enumerate the errors on pages 1-33. The statements concerning the sources of Recorde's text-books illustrate the careless editing of the work. Recorde's Ground of Arts was not "based on manuscripts entitled De origine artium and Arithmeticae principia" nor was his Pathway (sic) to Knowledge "printed from manuscripts entitled Geometriae semita and Theoremata Geometriae." Neither was the "Whetstone of Witte" "printed ... from his Secunda pars Arithmeticae." These works were all in English and the material is that current in continental texts of the same period. In passing, it must be said that Recorde 
was neither one of the "earliest" nor yet one of the "greatest mathematicians" of England.

In spite of the introduction which should have been prepared by one more familiar with the history of mathematics the work is highly to be commended, as eminently worthy a place in mathematical libraries.

Invitation is extended to subscribe to a guarantee fund to cover the cost of plates for Part III, Astronomy. American libraries are urged to send subscriptions to Part III to R. T. Gunther at Magdalen College, Oxford.

\section{C. KARPINSKI}

Geschichte der Elementar-Mathematik in systematischer Darstellung. By Johannes Tropfke. Berlin and Leipzig, Vereinigung Wissenschaftlicher Verleger. Bd. I: Rechnen. 1921. vi +177 pp. Bd. II: Allgemeine Arithmetik. 1921. $221 \mathrm{pp}$. Bd. III: Proportionen. Gleichungen. 1922. 151 pp. Bd. IV: Ebene Geometrie. 1923. 238 pp. The first edition of Tropfke's Geschichte der Elementar-Mathematik was published in 1902-1903, and was reviewed by J. W. A. Young in this BULletin.* The four volumes under review form part of a second edition, which is to include seven volumes, the last three being yet in press, or at least not yet available in this country. That the revision has been thoroughgoing is evidenced by the fact that the material corresponding to these four volumes occupied approximately 510 pages in the first edition, and has thus been expanded above 50 per cent; while the references to the literature in these four volumes number 4348, as compared with 1951 in the corresponding parts of the first edition.

And the advance made beyond the first edition is by no means merely quantitative. The author was fortunate in having the active assistance of G. Eneström and H. Wieleitner in the preparation of the new edition, and their names are a sufficient guarantee that no pains have been spared to make the work as complete and authoritative as possible. On nearly every page we find valuable additions to the information given in the first edition; while in several cases the point of view then adopted has been radically changed or even reversed.

To mention but a few of the changes: (1) In discussing the origins of the number system, use has been made of recent researches as to the knowledge of the Babylonians. An interesting detail is the fact (I, p. 15) that as early as 2500 B. C. the tables of Senkereh contain representations of very large numbers according to the sexagesimal system, the largest to date deciphered being $60^{8}+10 \cdot 60^{7}(=195955200000000)$. (2) The history of the development of technical terms is very largely expanded. (3) The independence of the work of the Hindus is in many cases questioned or denied in the second edition where it was accepted in the first; the researches of G. R. Kaye are largely responsible for the author's change of view here. (4) The account of complex numbers (II, 79-90) is entirely rewritten and considerably enlarged. (5) The discussion of the development of the theory of parallels (IV, 53-60) is a considerable improvement over that in the first edition, while it must be confessed that it still leaves something to be de-

*Vol. 12 (1905), pp. 138-140. 